\title{
AVALIAÇÃO DA APRENDIZAGEM NOS PROGRAMAS ONLINE DE FORMAÇÃO CONTINUADA DE EDUCADORES
}

LUCILA PESCE

\section{RESUMO}

0 presente texto apresenta uma reflexão sobre as possibilidades de efetivação da avaliação formativa, nos programas online de formação continuada de educadores. Para tanto, inicia com a tematização de conceitos relativos às abordagens de avaliação de aprendizagem, situando-as como decorrentes das diversas concepções de conhecimento. Prossegue, caracterizando a avaliação formativa e considerando sobre os dispositivos dos ambientes virtuais de aprendizagem que podem contribuir com a efetivação da avaliação formativa, no âmbito dos programas online de formação continuada de educadores. Finaliza, com a advertência de que, embora os dispositivos dos ambientes de rede ofereçam recursos para que se efetive a avaliação formativa, estas interfaces não se consubstanciam como elementos definidores da abordagem de avaliação da aprendizagem, nos programas online de formação continuada de educadores, mas sim a concepção educacional que os sustenta.

PALAVRAS-CHAVE: AVALIAÇÃO DA APRENDIZAGEM • FORMAÇÃO DE PROFESSORES • EDUCAÇÃO CONTINUADA • ENSINO A DISTÂNCIA. 


\section{RESUMEN}

En este texto se reflexiona sobre las posibilidades de ejecución de la evaluación formativa en programas online de formación continuada de educadores. Para ello, el ensayo comienza con los conceptos relacionados con los abordajes de evaluación del aprendizaje, colocándolos como consecuencia de las diferentes concepciones del conocimiento. Continúa con consideraciones acerca de la evaluación formativa, teniendo en cuenta los dispositivos de los entornos virtuales de aprendizaje que pueden contribuir con la evaluación formativa, en el contexto de los programas online de formación continuada de educadores. Concluye advirtiendo que a pesar de que los dispositivos virtuales proporcionen recursos para la realización de la evaluación formativa, estas interfaces no definen el enfoque del abordaje de la evaluación del aprendizaje de los programas online de formación continuada, pero sí la concepción educativa que los sustenta.

PALABRAS CLAVE: EVALUACIÓN DEL APRENDIZAJE •

FORMACIÓN DE PROFESORES • EDUCACIÓN CONTINUADA • ENSEÑANZA A DISTANCIA.

\section{ABSTRACT}

This paper reflects on the possibilities of formative evaluation in online continuing training programs for educators. It begins with a focus on concepts related to approaches of learning assessment, placing them according to different conceptions of knowledge. It continues, characterizing formative evaluation and considering the devices in virtual learning environments that may contribute to the effectiveness of formative evaluation in the context of online continuing training programs for educators. It concludes with the warning that although the network environment devices provide resources for formative evaluation to be carried out, these interfaces are not actually the defining elements of the learning assessment approach in online continuing training programs for educators, but rather the educational concept that supports them. 


\section{INTRODUÇÃO}

O presente texto traz uma reflexão sobre os desafios que se apresentam à avaliação da aprendizagem, nos programas online de formação continuada de educadores.

O recorte na formação continuada deve-se à concordância da autora do presente texto, com o posicionamento do documento referência da Conferência Nacional de Educação (CONAE, 2010), de que as práticas de educação online voltadas à formação dos educadores são recomendadas no âmbito da formação continuada. Assim como o documento referência, a autora deste texto acredita que a formação inicial de profissionais da educação em exercício desenvolvida por meio da educação online deve ocorrer se a outra opção for a ausência da oferta de cursos de ensino superior, na modalidade presencial. No dizer do documento: 
Embasado nesse entendimento, o presente texto, a partir dos estudos de Pesce (2008) sobre avaliação da aprendizagem na educação online, tematiza alguns conceitos sobre avaliação da aprendizagem, de modo a relacioná-los às distintas concepções educacionais. A seguir, busca caracterizar a avaliação formativa e avança para as especificidades da avaliação da aprendizagem nos ambientes virtuais de aprendizagem, com a intenção de refletir sobre os desafios que se descortinam para a implantação da avaliação formativa, nos programas online de formação continuada de educadores.

\section{CONCEPÇÕES DE AVALIAÇÃO DA APRENDIZAGEM: PRIMEIRAS ANOTAÇÕES}

Tendo como ponto de partida a ideia de que as concepções de avaliação alteram-se, em concordância com as demandas de cada sociedade, em um determinado momento histórico, resgata-se, a partir dos estudos de Alves (2004), uma brevíssima discussão das principais tendências de educação e suas implicações no campo da avaliação da aprendizagem.

Alves (ibid.) aponta cinco perspectivas ideológicas das quais emanam distintas concepções de avaliação de aprendizagem. Cada uma dessas concepções relaciona-se a diferentes primados.

O primado da consciencialização surge no século XIX, nos Estados Unidos. Anos mais tarde, emerge também na Europa, em uma atitude de contraponto às práticas tradicionais de avaliação, que se erguem em meio à busca de métodos mais objetivos para comprovar a eficácia escolar.

O primado da psicometria esteve plenamente em vigor entre 1900 a 1930. Todavia, este primado exerce influência até os dias atuais, como, por exemplo, em situações educacionais em que a avaliação formal se sobrepõe às demais atividades desenvolvidas no cotidiano do trabalho educativo.

O primado da congruência vigorou entre as décadas de 1930 e 1950 e se baseia na arquitetura teórica de Ralph Tyler. De acordo com este primado, a avaliação não mais se restringe aos instrumentos de medida, mas passa a ser concebida como processo inerente ao ensino e à aprendizagem. Por essa razão, não somente o desempenho final do aluno é levado 
em consideração, mas, do mesmo modo, o seu processo de aprendizagem.

O primado da expansão vigorou entre os anos de 1958 e 1972, de modo a apoiar o desenvolvimento dos centros de estudo e das associações especializadas em avaliação do sistema escolar. Com ele surgem os primeiros estudos das divergências entre as concepções de avaliação somativa e formativa.

O primado da profissionalização surge em 1972, conferindo à avaliação uma natureza sistemática, com quatro etapas distintas:

- Avaliação de contexto: voltada à identificação de uma determinada situação de aprendizagem.

- Avaliação de entrada: prevê alguns indicadores iniciais, para o trabalho avaliativo.

- Avaliação do processo: acompanha o desenvolvimento do processo de construção de conhecimento do aprendiz.

- Avaliação do produto: busca investigar em que medida as finalidades pretendidas de fato conseguem ser atingidas.

Convém sinalizar que, apesar da distinção dos primados acima anunciados, tais enfoques coexistem até hoje, nas práticas de avaliação da aprendizagem.

Alves (ibid.) esclarece que, assim como os primados auxiliam a compreensão dos distintos enfoques de avaliação da aprendizagem, um delineamento dos paradigmas educacionais existentes e de seus reflexos nas práticas de avaliação também pode contribuir com o melhor entendimento do tema.

O paradigma objetivista carrega consigo aspectos da abordagem comportamentalista e se faz presente nas práticas curriculares positivistas, uma vez que se volta às metas a serem atingidas e a desempenhos a serem observados, na etapa final do processo de ensino e aprendizagem. Segundo este paradigma, o ensino deve ser respondente às necessidades sociais, notadamente as voltadas ao desenvolvimento econômico e tecnológico. Nesse contexto, a avaliação é entendida como técnica de mensuração da aprendizagem. Em função disso, ela se vê sempre associada ao controle externo; portanto, os contextos e as características dos estudantes não são tão considerados.

A seu turno, o paradigma subjetivista concebe o conhecimento intimamente imbricado a elementos subjetivos. Nessa 
perspectiva, o estudante consubstancia-se como ponto basilar aos processos educativos e a avaliação situa-se como prática social, uma vez que busca acompanhar o processo de desenvolvimento do aluno em sala. Desse modo, a avaliação assume a função reguladora, de acompanhamento e de autoavaliação.

Por fim, o paradigma dialético (também denominado interacionista) volta-se à superação da dualidade entre o sujeito cognoscente e o objeto cognoscível. Por conseguinte, a avaliação ergue-se em meio à dimensão praxiológica e emancipadora, sendo concebida como fenômeno em devir, que deve ser constantemente construída e reconstruída, com o objetivo de se tornar um instrumento cada vez mais apurado, no tocante à avaliação da aprendizagem dos estudantes. Aproximando-se de alguns dos princípios e pressupostos da avaliação formativa (conforme esclarecido no item a seguir), o paradigma dialético advoga a ideia de que as práticas de avaliação devem sempre tentar buscar responder até que ponto os instrumentos de avaliação estão afinados aos fins educacionais a que se destinam.

\section{AVALIAÇÃO FORMATIVA: CONSIDERAÇÕES PRELIMINARES}

O rápido panorama das concepções educacionais e seus desdobramentos nas práticas de avaliação de aprendizagem convidam à contextualização da avaliação formativa.

A proposta de avaliação formativa contrapõe-se à proposta de avaliação somativa, tendo-se em vista que esta última atenta para o produto apresentado pelo estudante, concebendo este produto como representativo dos seus avanços. Esta proposta de avaliação da aprendizagem não leva em conta fatores como o interesse do estudante pelo tema trabalhado, a participação em sala de aula, as contribuições para a discussão coletiva. Os indicadores de avaliação de aprendizagem do aluno são os produtos por ele apresentados. Essa abordagem de avaliação ancora-se na classificação do aluno, em relação aos demais colegas, sendo particularmente utilizada nas práticas de avaliação classificatória, como os exames vestibulares e os processos de seleção de cargos ofertados no mercado de trabalho.

À contramão da avaliação somativa, a avaliação formativa considera as distintas estratégias de acompanhamento da 
aprendizagem, erguendo-se em meio à perspectiva reguladora das estratégias pedagógicas e das atividades discentes. Nessa perspectiva, a avaliação formativa trabalha com a díade "etapa diagnóstica e tratamento didático”, de modo a destacar a fecundidade da avaliação para a promoção da metarreflexão do estudante (sobre suas etapas de construção do conhecimento) e para a reflexão docente sobre o programa de ensino e aprendizagem, redimensionando-o, em função dos dados oriundos das avaliações dos estudantes.

A avaliação formativa prevê as seguintes etapas de operacionalização: coleta e interpretação de informações; diagnóstico das dificuldades de aprendizagem; adaptação das atividades de ensino, em função da interpretação dos dados coletados (ALvES, 2004).

Alves (2004) esclarece a relação intrínseca entre a avaliação formativa e as distintas concepções de conhecimento, com destaque para duas:

a. concepção cognitivista: investiga os processos mentais que intervêm na relação entre questão e resposta. Ao considerar o desenvolvimento das funções psicológicas superiores, a intervenção do professor volta-se à mobilização do estudante, para refletir, retrospectiva e prospectivamente, sobre o seu processo mental, na aprendizagem do tema trabalhado;

b. concepção diagnóstica: enfatiza a seleção de informações que dizem respeito às dificuldades de aprendizagem. Mais que verificar quanto o aluno aprendeu, a concepção diagnóstica sinaliza a ideia de que a verificação das dificuldades de aprendizagem do estudante situa-se como referência, na revisão das estratégias de ensino.

Em cada uma das concepções delineiam-se as etapas a seguir: a) concepção, preocupada com a compreensão do que se espera em relação ao aluno; b) antecipação do que deverá ser feito para que se atinja o objetivo desejado; c) planificação, momento de escolha de estratégias e dos procedimentos; d) execução, realização propriamente dita; e) avaliação, compreendida como parte integrante do ato educativo.

Em sintonia com Alves (2004), Abrecht (1995) destaca que, para a avaliação formativa, é primordial a compreensão do diagnóstico do aprendizado do aluno, uma vez que tal compreensão habilita o 
professor à tomada de decisão sobre as ações a desenvolver, em função dos objetivos a serem alcançados.

Para Luckesi (2005), a avaliação da aprendizagem implantada segundo a abordagem inclusiva deve se orientar para o pleno desenvolvimento do estudante, o que significa ir além da seleção e da aprovação ou reprovação do educando. Para o pesquisador, a acolhida ao aluno ancora a prática educativa, incluindo-se as práticas de avaliação. Segundo o autor, a qualificação do estágio em que o aluno se encontra é apenas uma das etapas da avaliação, que só se realiza plenamente com a tomada de decisão, a partir da situação diagnosticada. Com base em tais considerações, o autor aponta três elementos constituintes do processo de avaliação: dados relevantes; instrumentos; utilização dos instrumentos.

Para o autor (ibid.), o diagnóstico deve ser realizado por intermédio da coleta de dados importantes ao estado de aprendizagem do aluno, no tocante ao objeto em questão, na avaliação. É ter ciência do que o estudante já sabe sobre determinado objeto do conhecimento, considerando os dados essenciais como os definidos no planejamento de ensino e executados na prática educativa.

O pesquisador salienta ser necessário atentar para que os instrumentos de avaliação da aprendizagem estejam adequados: ao tipo de conduta e de habilidade que estão sendo avaliadas; aos conteúdos primordiais planejados e efetivados no processo de ensino; ao processo de aprendizagem do estudante como um todo; à linguagem, com vistas a garantir que o aprendiz compreenda com clareza o que foi solicitado. Por isso, os instrumentos de avaliação devem ser percebidos como recursos de coleta de dados e não como instrumentos de controle disciplinar. Nessa perspectiva, Luckesi (ibid.) alerta sobre como um instrumento inadequado pode conduzir a um diagnóstico equivocado e, consequentemente, a uma tomada de decisão distorcida.

É oportuno frisar que os princípios da avaliação formativa pautam-se: a) em um caráter processual, no qual professor e estudantes são sujeitos ativos no processo de construção de conhecimento; b) nos centros de interesse, a partir dos temas primordiais a uma dada área; c) na elaboração de objetivos iniciais, a partir do diagnóstico do alunado, levando-se em conta seus 
anseios e necessidades; d) no acolhimento dos objetivos oriundos do processo de formação; e) na avaliação dialogada, que integra a avaliação do desempenho dos estudantes, a autoavaliação de cada um deles e sua avaliação sobre o curso, em distintos momentos da vigência do mesmo; f) na abordagem diagnóstica, que revê as ações de mediação; g) na tessitura de um quadro teórico-metodológico contribuinte à formação do aprendiz.

As considerações relativas à avaliação formativa instigam à seguinte questão: até que ponto esta vertente de avaliação da aprendizagem pode se efetivar nos programas online de formação continuada de educadores?

\section{AVALIAÇÃO DE APRENDIZAGEM NOS PROGRAMAS ONLINE DE FORMAÇÃO CONTINUADA DE EDUCADORES: APONTAMENTOS INICIAIS}

No que diz respeito à avaliação de aprendizagem nos programas online de formação continuada de educadores, é importante trazer à baila as especificidades dos ambientes virtuais de aprendizagem, considerando-se os recursos dos ambientes de rede que possibilitam a avaliação formativa. Para tal, o presente texto tece um intertexto, a partir de apontamentos de pesquisadores dessa temática, como Moreira (2003), Palloff; Pratt (2002; 2004), Silva (2006) e Santos (2006).

Ciente de que a avaliação desempenha uma função formativa nos processos de aprendizagem, Moreira (2003) salienta que a avaliação não deve se restringir ao processo de aprendizagem dos estudantes, mas também contemplar a atuação dos professores. Para a autora, a avaliação da aprendizagem de programas de formação, presenciais ou online, deve buscar o imbricar das duas vertentes descritas a seguir:

- Vertente diagnóstica: deve ocorrer logo no começo do programa de formação, por meio da aplicação de questionários ou fichas de inscrição, com o intuito de elaborar um perfil do grupo em tela. A metodologia e as ferramentas pedagógicas devem ser definidas a partir desse diagnóstico.

- Vertente formativa: pautada em uma perspectiva processual, esta vertente deriva da visão construtivista. 
O acompanhamento do desempenho do estudante é primordial às intervenções diferenciadas do professor. A avaliação formativa contribui com a regulação do aluno, em distintas instâncias, a saber: retroativa (mediante verificação dos acontecimentos prévios, ajustando tarefas e situações de aprendizagem), interativa (de caráter processual, permitindo intervenção em tempo real) e proativa (comprometida com o engajamento dos estudantes nas atividades propostas). Em complemento à regulação, Moreira destaca a importância da autorregulação dos estudantes, graças às possibilidades de fortalecimento das capacidades de gestão dos seus processos de aprendizagem, por intermédio de situações comunicativas, que abarquem os estudantes em situações de interação e de tomada de decisão.

Todavia, Moreira (2003) lembra que muitos programas de formação ainda se voltam à avaliação somativa, notadamente articulada à mensuração. Pautada na aferição do desempenho do aprendiz, a avaliação somativa volta sua atenção para a objetividade do instrumento de medida e, por conseguinte, ao produto. Ao fazê-lo, desconsidera a participação do aluno como um dos indicadores primordiais à avaliação de desempenho.

Em defesa da abordagem de avaliação processual, Moreira (2003) delineia distintas estratégias e instrumentos de avaliação, dentre os quais são destacados neste texto: a) o portfólio, compreendido como espaço de registro de todas as etapas de aprendizagem do aluno; b) a autoavaliação, que permite ao estudante conscientizar-se dos vários aspectos relacionados à sua aprendizagem; c) o trabalho final, que expressa a capacidade de organização estrutural dos conteúdos trabalhados; d) a discussão colegiada, entendida como compartilhamento de avaliações entre professores e coordenação; e) o correio eletrônico, que favorece a visibilidade e o acompanhamento do processo de ensino-aprendizagem.

Em um estudo dos processos de avaliação de aprendizagem nos programas de formação online, Silva (2006), amparado nas pesquisas de Hoffmann (2004), releva as quatro dimensões da avaliação mediadora. $\mathrm{O}$ autor destaca que a avaliação mediadora se faz presente nas etapas de formação. A avaliação 
é considerada mediadora quando as análises dos resultados parciais de avaliação vão sendo incorporadas à formação. Esse enfoque de avaliação é tido como o meio através do qual os educadores reiteram ou modificam suas práticas pedagógicas e os estudantes ratificam ou retificam suas estratégias de aprendizagem. Nesse contexto, Silva (2006) delineia as quatro dimensões da avaliação mediadora:

a. o contexto sociocultural do aluno: quem é, de onde vem, com quem vive o aluno?

b. os saberes significativos: temas abordados em consonância com o contexto sociocultural do aluno;

c. as questões epistemológicas: como se aprende, em que idade, quais suas teorias de conhecimento?

d. o cenário educativo/avaliativo: anuncia o imbricar das concepções de avaliação com as educativas.

Com base nestas quatro dimensões, o pesquisador salienta alguns meios para se efetivar a interatividade nos processos de avaliação da aprendizagem em ambientes online, dentre os quais se destacam: a) dar oportunidade aos alunos para realizar tarefas em grupos; b) propor aos aprendizes tarefas afeitas às etapas anteriores; c) não atribuir conceitos classificatórios a essas tarefas; d) trabalhar com conteúdo, de forma clara; e) criar alternativas pedagógicas na aplicação dos modelos de avaliação; f) reunir sugestões para as práticas de alunos e professores, para rever a autonomia da construção da aprendizagem; g) trabalhar com os alunos a visão crítica das atitudes comunicacionais; h) mobilizar a interação de professores e web designers, nas distintas etapas dos programas de formação.

Ancorado nos princípios comunicacionais, Silva (2006) sinaliza alguns fatores que podem contribuir com a melhoria da aprendizagem em programas de formação online, dentre os quais o presente texto destaca: a) convidar o aluno à livre criação de conteúdos e críticas; b) distribuir as mensagens, de forma que os estudantes investiguem as respostas, como sujeitos ativos do processo de construção do conhecimento; c) ampliar a participação dos aprendizes, de modo que eles possam interferir na mensagem e construir a aprendizagem em um meio de comunicação; d) produzir conteúdos, conjuntamente; estimular a participação dos alunos, de acordo com 
seus respectivos perfis; propor conteúdos de aprendizagem como obra aberta; e) viabilizar a interatividade em tempo real; f) disponibilizar e incentivar expressões artísticas com jogos, simulações e objetos de aprendizagem; g) avaliar os estudantes segundo critérios estabelecidos inicialmente; h) considerar o histórico quantitativo e qualitativo; i) mobilizar os alunos para a autoavaliação e para a avaliação coletiva.

Tais proposições esclarecem a concepção de Silva (2006) de que a colaboração constitui-se como instância basilar, na construção da comunicação, do conhecimento e dos processos de avaliação da aprendizagem.

A seu turno, Santos (2006) reflete sobre os desafios da web, em face da avaliação da aprendizagem em cursos online. Ao fazê-lo, a pesquisadora sinaliza a íntima relação entre a qualidade desta avaliação e a possibilidade de as ferramentas computacionais gerarem produtividade e automatização. Nesse movimento, Santos (2006) destaca o relevante papel dos instrumentos informais de avaliação, como a participação dos estudantes em atividades e debates, por exemplo.

A autora traz um importante alerta: que avaliação da aprendizagem dos cursos online, mormente os desenvolvidos em larga escala, tem incidido sobre a avaliação do desempenho individual, em testes objetivos. Por fim, Santos (2006) aborda a dificuldade em se conciliar o respeito à liberdade de tempo e espaço do estudante em formação online, com os cronogramas dos cursos, que tendem a reproduzir a organização acadêmica presencial, à medida que se balizam em unidades de aprendizagem.

Para Palloff \& Pratt (2002), a avaliação formativa possibilita aos professores rever os programas de formação online. Ambos destacam que a aprendizagem centrada no aluno requer que a avaliação insira-se nas atividades de aula e nas interações dos aprendizes e destes com os professores. Nessa perspectiva, os pesquisadores destacam o diálogo ocorrente nos cursos online, como importante material de avaliação da aprendizagem.

Palloff \& Pratt (2002) salientam a importância de outros fatores para a efetivação da avaliação da aprendizagem sob enfoque formativo, tais como: a) a atenção nas necessidades e nos objetivos identificados pelos alunos no começo do curso; b) o nível educacional; c) a familiaridade com as tecnologias 
da informação e comunicação e com a aprendizagem online; d) a participação; e) as questões relacionadas à escrita.

Em publicação posterior, os pesquisadores (2004) avançam na discussão acerca da avaliação da aprendizagem em cursos online, apontando que cursos diferenciados devem prever ações igualmente diferenciadas de avaliação, erguidas em meio a princípios que definem a avaliação como um processo: a) centrado no aluno, situando-o como responsável pela aprendizagem; b) dirigido pelo professor, quando é este profissional quem decide como e o que avaliar, de que modo responder ao aluno, como tornar disponíveis as informações de avaliação no início de cada módulo e que critérios definir; c) mutuamente benéfico, por incentivar a avaliação colaborativa; d) formativo, por compreender a participação dos alunos nos momentos de avaliação e por buscar atender às necessidades e analisar as necessárias mudanças.

Para Palloff \& Pratt (2002), a avaliação final deve incluir: a experiência no curso; a orientação recebida; o conteúdo trabalhado; os debates com outros alunos e com o professor; a autoavaliação (com base na participação e no desempenho); a avaliação da plataforma virtual utilizada; o suporte técnico e o acesso aos recursos da plataforma. Por fim, os pesquisadores alertam para a relevância de o professor que atua em ambiente online: levar em consideração a necessidade e as opiniões do estudante sobre sua aprendizagem; responder ao aluno da maneira mais oportuna possível; proceder às readequações de percurso, enquanto o curso ainda vigora; valorizar a opinião dos estudantes, esclarecendo que sua aprendizagem emerge do esforço conjunto entre ambos os sujeitos sociais envolvidos: alunos e professor.

As considerações dos autores anunciados neste texto levantam algumas reflexões sobre os limites e as possibilidades de se efetivar a avaliação formativa nos programas online de formação continuada de educadores, com base nos recursos oferecidos pelos ambientes virtuais de aprendizagem.

Apesar das especificidades de cada um dos teóricos mencionados no presente texto, é possível destacar dois pontos de convergência: a pertinência da avaliação da aprendizagem formativa para a consolidação dos programas online de formação continuada de educadores e as estratégias de uso dos recursos 
dos ambientes de rede, para a efetivação desta abordagem de avaliação nos aludidos programas.

As ideias anunciadas pelos autores mencionados fornecem importantes subsídios ao aprofundamento da discussão sobre as possibilidades de se efetivar a avaliação da aprendizagem formativa nos programas online de formação continuada de educadores, a partir de três categorias destacadas neste texto: a) metarreflexão e avaliação; b) avaliação, leitura e escrita; c) situação de interlocução e avaliação.

\section{METARREFLEXÃO E AVALIAÇÃO}

Tomando-se por base as possibilidades de registro do raciocínio do estudante, as plataformas virtuais de interação situam-se como recurso à compreensão dos processos cognitivos do aprendiz. Tal ideia sustenta-se em função do suposto aumento de complexidade nas elaborações conceituais dos estudantes poder se efetivar quando eles, mediante representação de seus pensamentos na tela do computador, conseguem atingir o necessário distanciamento das suas elaborações mentais, para promover uma reflexão sobre elas, o que possibilita a construção da competência metarreflexiva.

Esse processo de construção da competência cognitiva, integrado à possibilidade de o educador em formação rever seu percurso no curso, pode contribuir com o adensamento da sua capacidade de reflexão sobre o seu próprio pensamento. $\mathrm{O}$ olhar retrospectivo (ativado na reflexão sobre o que e de que modo ele produziu) pode balizar sua prospeç̧ão (ativada na reflexão sobre o que e de que forma ele deve fazer, a partir de então). Esse movimento, ao situar o educador em formação como sujeito responsivo da sua aprendizagem, situa-se em uma dimensão formativa. Em outras palavras, a avaliação formativa auxilia o formador a intervir de modo mais adequado na aprendizagem dos educadores em formação continuada, em um movimento em que os mesmos se pautam em uma atitude reflexiva sobre seu processo de construção do conhecimento.

Nessa perspectiva é importante destacar: ao invés de uma utilização dos ambientes virtuais de aprendizagem (AVA) que iniba a autoexpressão dos educadores em formação é fundamental que se privilegie o diálogo e as manifestações pessoais. 
Para tanto, é oportuno que o programa de formação peça ao estudante que se autoavalie, tomando por base suas produções arquivadas em dispositivos do AVA, como o portfólio, por exemplo. Outro possível recurso contribuinte à avaliação metarreflexiva é o memorial reflexivo ou o diário de bordo, pelas possibilidades de registro das impressões do professor em formação acerca do seu percurso no curso, em uma perspectiva que delineie os avanços alcançados e os desafios a enfrentar.

Entretanto, para que tais questões não sejam tratadas em uma perspectiva reducionista, traz-se à baila o alerta de uma das formadoras entrevistadas na pesquisa de Pesce e Brakling (2006): a necessidade de o formador estar atento ao retorno que dará ao aluno, nas autoavaliações contidas no memorial reflexivo ou no diário de bordo. No entendimento da formadora entrevistada, a autoavaliação do aluno, se concebida como exercício solitário, corre o risco de perecer em si mesma.

Para ampliar a discussão sobre o sentido da expressão "avaliação como exercício solitário” é oportuno situar a avaliação formativa como instrumento relevante à formação do educador em formação e como processo de construção do saber didático do formador. Nessa perspectiva, a avaliação percebida como exercício solitário perde seu sentido, quando percebida com fim em si mesma, ao invés de concebida como promotora de mudanças nas estratégias didáticas do formador e nas estratégias de aprendizagem do educador em formação. Por essa razão, o resultado de avaliação deve ser objeto de discussão e de reflexão conjunta de ambos. A isso se alia a interlocução do educador em formação com seus colegas e com o formador, como importante instância de ampliação das suas possibilidades metarreflexivas.

\section{AVALIAÇÃO, LEITURA E ESCRITA}

Uma importante consideração sobre os desdobramentos da produção escrita nos processos de avaliação da aprendizagem é a possibilidade de o formador acompanhar o percurso dos educadores em formação, em todas as etapas da aprendizagem. Isso é possível, pois o registro das atividades do professor em formação - produção textual, listas de atividades, interação em chats e fóruns de discussão, só para citar alguns exemplos - permite que o formador faça um diagnóstico da aprendizagem do educador 
em formação e detalhado, no caso de um dos registros ser tomado como objeto específico de avaliação. Em outras palavras, o registro das produções dos educadores em formação, no AVA, viabiliza um mapeamento detalhado do percurso dos educadores em formação, por pwarte do formador; fato que pode otimizar suas possibilidades de intervenção. Mas, para que isso aconteça, é importante que o formador atente se, de fato, o registro em questão reflete a aprendizagem dos educadores em formação, já que a tônica da linguagem escrita dos programas de formação online pode se constituir como fator inibidor da participação dos sujeitos com certa dificuldade de escrita. Sabe-se que a estrutura sintático-semântica (referente à lógica estrutural do texto e à construção do seu significado) da língua escrita tende a ser mais complexa que a da oralidade. Esse fato exige do escritor saberes linguísticos, que muitas vezes estão em dissonância com seus demais saberes.

Para ampliar as considerações do parágrafo anterior é importante lembrar as ideias de Souza (1991) sobre as distintas lógicas da leitura e da composição. Segundo a pesquisadora, a composição é canalizadora e funciona em uma lógica dedutiva, que envolve atividades analíticas fundadas na disjunção e na distinção. A leitura, a seu turno, dissemina e se ergue em meio a uma lógica associativa, que abarca atividades sintéticas, embasadas nas articulações e nas associações.

Góes (1995), em reflexão sobre a elaboração de textos, por escritores iniciantes, sinaliza que a escrita situa-se como instância de relato de conhecimento, diferentemente do que ocorre com os escritores mais avançados, para quem a escrita envolve transformação do conhecimento. Para Góes (1995), o professor deve estar sempre atento se, de fato, o registro consegue ser um instrumento que represente com fidedignidade a complexidade da aprendizagem dos alunos. Nessa perspectiva, é preciso que a avaliação de aprendizagem, nos ambientes virtuais de aprendizagem, considere as dificuldades de escrita, pois, do contrário, o professor corre o risco de avaliar de modo equivocado e, em decorrência, de proceder a intervenções inadequadas.

No que diz respeito à elaboração dos saberes conceptuais, Volochinov e Bakhtin (2011) sinalizam que a apropriação da palavra alheia situa-se como processo, que envolve diferentes 
etapas. Inicialmente, é muito comum o uso da palavra alheia, ocorrente na cópia literal de um dado texto, pelos estudantes. Em um segundo momento, os alunos fazem uso da palavra própria-alheia, quando escrevem sobre um dado conceito, parafraseando as ideias dos autores de referência. Somente no último estágio os estudantes assumem-se como autores do próprio texto, versando sobre algo com suas próprias palavras, em diálogo profícuo com os autores estudados. Nessa perspectiva, quando um estudante reproduz o discurso alheio, com transcrição literal de um dado excerto, é importante que o professor problematize tal postura discente, para que o mesmo tome consciência de que a reprodução da palavra alheia consubstancia-se como etapa inicial da aprendizagem, uma vez que este movimento ainda o situa como reprodutor de conhecimento de outrem. Tal problematização deve integrar a avaliação formativa, no destaque dado à autoavaliação discente. Esse movimento também deve se fazer presente nos programas online de formação continuada de educadores.

\section{SITUAÇÃO DE INTERLOCUÇÃO E AVALIAÇÃO}

A pesquisa de Pesce e Brakling (2006) destaca que a construção dos saberes conceituais ergue-se em meio aos de vínculos de confiança entre professor e estudante, o que permite que a aprendizagem seja avaliada por ambos e seus respectivos esforços sejam reavaliados: as estratégias de ensino dos professores e os procedimentos de aprendizagem do aluno.

A avaliação dos saberes de natureza conceitual e praxiológica vincula-se aos tipos de instrumentos utilizados. Os instrumentos da avaliação operatória (RonCA; TERzI, 1991), por exemplo, remetem os alunos à resolução de problemas. Nos ambientes virtuais de aprendizagem, pode haver a proposição de uma avaliação pautada em uma situação-problema. A análise de uma situação prática invita o estudante a acionar seus saberes conceptuais e praxiológicos, uma vez que a ele é requerido mobilizar conceitos para refletir sobre a prática.

As interações online dos programas de formação continuada de educadores, quando bem mediadas pelo formador, consubstanciam-se como campo propício à avaliação formativa; pela possibilidade de efetivo diálogo entre ambos os 
sujeitos sociais envolvidos, na problematização das posições de ambos e nas devolutivas que o formador realiza. Todavia, para que essa perspectiva se efetive, é necessário que o programa de formação online trabalhe com um número adequado de educadores por formador e aufira a ambos autonomia sobre o tempo de interação (PeSCE, 2007). Nessa perspectiva, o acúmulo de tarefas a serem realizadas em tempo exíguo traz reflexos nefastos para a interlocução, dentre os quais se destacam a demora nas devolutivas do professor e, em decorrência, a ausência de sincronia entre as situações de interlocução e a construção de conhecimento do aluno (PeSCE, 2007).

A concepção educacional de um determinado programa online de formação continuada de educadores é o que dá suporte ao uso das interfaces do AVA, para a avaliação de aprendizagem. Por isso é preciso que a concepção de avaliação seja convergente com a concepção de educação subjacente ao programa. A despeito de a maioria dos ambientes virtuais de aprendizagem oferecer condições para que a prática da avaliação formativa se efetive, ela só ocorrerá se a concepção educacional do programa online de formação continuada de educadores estiver em coerência com esta abordagem de avaliação.

A quantificação de dados - de acesso ao ambiente, do número de vezes que o estudante participou do fórum, do tempo de navegação no AVA, só para citar alguns exemplos - só contribuirá com a avaliação formativa, se vinculada a dados qualitativos oriundos do acompanhamento do processo de aprendizagem do estudante, nas distintas interfaces da plataforma.

A concordância com Silva (2006) de que as situações de interlocução são primordiais à consolidação da avaliação formativa conduz à ideia de que a metodologia de mediação situa-se como importante instância, para que a avaliação formativa se efetive nesse movimento dialógico.

Outra questão relevante para a consolidação das práticas de avaliação formativa é a orientação didática do trabalho do formador. Como destaca Libâneo (1994), dentre outros pesquisadores da área, o conhecimento didático pressupõe o estudo teórico da organização das aprendizagens no processo educacional, com destaque para a definição de instrumentos utilizados nas situações de aprendizagem e a clara percepção da relevância 
das atividades para os tipos de saberes a serem construídos. Por essa razão, a escolha dos instrumentos de avaliação não pode ser aleatória. $\mathrm{O}$ formador deve se questionar em que medida um determinado instrumento está adequado para avaliar uma dada situação de aprendizagem dos educadores em formação. Uma possível estratégia é refletir sobre os saberes requeridos nessa situação de aprendizagem, para, então, pensar se os instrumentos de avaliação elencados conseguem explicitar o modo como tais saberes foram construídos.

Como se pode observar, a efetivação de uma prática de avaliação formativa nos programas online de formação continuada de educadores fundamenta-se em um conjunto de fatores, queintegra a concepção de educação, as estratégias didáticas, a metarreflexão docente e discente, a situação de interlocução, a competência de escrita dos educadores em formação, o tempo que eles dispõem para realizar as atividades propostas e os espaços sociais por eles ocupados. Esses e outros fatores devem ser levados em consideração, no planejamento e no desenvolvimento dos programas online de formação continuada de educadores.

\section{CONCLUSÕES PROVISÓRIAS}

Em um momento político de fomento a programas de formação continuada de educadores, por meio da educação online, este texto tem o objetivo de refletir sobre as possibilidades de se efetivar a avaliação formativa, em tais programas. Para tal, foi traçado um brevíssimo painel das distintas concepções de avaliação e se avançou para o estudo das especificidades dos ambientes virtuais de aprendizagem.

A constelação teórica delineada no artigo sinaliza que a avaliação da aprendizagem formativa contribui, a um só tempo, com a melhoria da intervenção do formador na aprendizagem dos educadores em formação e com a construção da atitude reflexiva desses profissionais da educação, sobre seu percurso no programa de formação.

Os dispositivos dos ambientes virtuais de aprendizagem portfólio, memorial reflexivo, diário de bordo etc. - podem se consubstanciar como recursos facilitadores da metarreflexão dos educadores em formação. O registro das atividades dos educadores 
nos distintos dispositivos da plataforma virtual permite ao formador mapear a aprendizagem do grupo. Essa circunstância amplia suas possibilidades de intervenção pedagógica.

A análise realizada, com base na experiência da pesquisadora em diversos programas online de formação continuada de educadores e na revisão de literatura ora elaborada, deflagra que a maioria dos ambientes virtuais de aprendizagem oferece recursos para que se efetive a avaliação formativa. Entretanto, os dispositivos, em si, enquanto recursos semióticos, são despidos de juízo de valor. Um mesmo ambiente virtual de aprendizagem pode ser utilizado, com vistas a possibilitar a avaliação somativa ou formativa, a depender da racionalidade que fundamenta um dado programa online de formação continuada de educadores.

Os estudos de Pesce (2007) sinalizam a tese habermasiana, que é contrária à racionalidade instrumental e favorável à racionalidade comunicativa. A primeira ancora-se no sujeito egologicamente constituído e se volta aos fins de controle e dominação. A segunda, erguida em meio à materialidade histórica dos sujeitos sociais, respeita o mundo da vida desses sujeitos e busca o entendimento mútuo provisório, no estreitamento das relações intersubjetivas voltadas à emancipação. Nesse movimento, a linguagem situa-se como medium regulador do entendimento mútuo, como forma de ação social. A busca de consenso habermasiano é perseguida com o exercício do argumento e da problematização, em contexto intersubjetivo (em que se elaboram argumentos livres de coação) e provisório (porque aberto a outros níveis de compreensão e entendimento).

O uso dos ambientes virtuais de aprendizagem, nos programas online de formação continuada de educadores, pode viabilizar a perspectiva interacionista (que costuma utilizar a avaliação formativa) ou autoinstrucional (que costuma utilizar a avaliação somativa). Não são os recursos técnicos dos ambientes de rede que estão em jogo, mas o uso que deles se faz. E o que dá sustentação a um ou a outro uso de tais dispositivos é uma premissa anterior: a concepção educacional (funcionalista ou culturalista) e o tipo de educador que se pretende formar.

O uso dos ambientesvirtuais de aprendizagem, quando voltado à emancipação social, preconiza a importância da democratização 
do acesso ao conhecimento socialmente legitimado. Isso pode ocorrer, por exemplo, quando educadores em formação, oriundos de todos os estados brasileiros têm a possibilidade de assistir à aula magna de um professor emérito de uma universidade de expressão acadêmica. Pode também ocorrer quando educadores com circunstâncias históricas semelhantes compartilham ideias, em resposta aos desafios que se lhes apresentam, ainda que estejam distantes geograficamente. A vertente educacional emancipadora releva o valor da ampliação da perspectiva alteritária, quando as interações online permitem a socialização de sujeitos sociais que, embora compartilhem alguns elementos sociais, pertencem a habitus culturais e geográficos distintos.

Todavia, boa parte dos programas de formação online de educadores ainda se ergue em meio à racionalidade instrumental (Zuin; Pesce, 2010). Baseados nessa racionalidade, tais programas tentam otimizar custos, por meio da redução de recursos humanos, mediante estratégias, como atendimento massivo e retomada da formação em cadeia, como adverte Freitas (2002). Romper com os ditames econômicos e pensar em programas de formação online de educadores erguidos em meio à racionalidade comunicativa e à avaliação formativa revela-se como um dos maiores desafios impostos a gestores e educadores que pensam e atuam nos programas online de formação continuada de educadores.

\section{REFERÊNCIAS BIBLIOGRÁFICAS}

ABRECHT, R. A Avaliação formativa. Portugal: ASA, 1995.

ALVES, Maria Palmira. P. Os Paradigmas e as perspectivas atuais de avaliação. In: 2004. p. 31-86.

. Currículo e avaliação: uma perspectiva integrada. Porto: Porto,

BAKHTIN, M. (1979). Estética da criação verbal. São Paulo: Martins Fontes, 1997.

CONFERÊNCIA NACIONAL DE EDUCAÇÃO, 2010, Brasília, DF, Construindo o Sistema Nacional Articulado de Educação: o Plano Nacional de Educação, diretrizes e estratégias: documento final. Brasília, DF: MEC, 2010. 
GÓES, Maria Cecília R. de. A Criança e a escrita: explorando a dimensão reflexiva do ato de escrever. In: SMOLKA, Ana Luiza; GÓES, Maria Cecília R. de (Org.). A Linguagem e o outro no espaço escolar. Campinas: Papirus, 1995. p. 101-119.

HOFFMANN, J. Avaliação: mito e desafio - uma perspectiva construtivista. Porto Alegre: Mediação, 2004.

LIBÂNEO, J. C. Didática. São Paulo: Cortez, 1994.

MOREIRA, M. O Processo de avaliação em cursos a distância: reflexão. In: GIUSTA, Agnela da S.; FRANCO, I. M. (Org.). Educação à distância: uma articulação entre a teoria e a prática. Belo Horizonte: PUC Minas, 2003. p. 73-87.

LUCKESI, C. Avaliação da aprendizagem escolar: estudos e proposições. 16.ed. São Paulo: Cortez, 2005.

PALLOFF, R.; PRATT, K. Avaliação. In: Construindo comunidades de aprendizagem no ciberespaço: estratégias eficientes para salas de aula on-line. Porto Alegre: Artes Médicas, 2002. p. 175-189.

Avaliação dos alunos e do curso. In: O Aluno virtual: um guia para trabalhar com estudantes on-line. Porto Alegre: Artes Médicas, 2004. p. 111-124.

PESCE, L. As Contradições da institucionalização da educação a distância, pelo Estado, nas políticas de formação de educadores: resistência e superação. 2007. 201f. Tese. (Pós-doutorado em Filosofia e História da Educação) - Unicamp, Campinas, 2007.

Avaliação formativa: desafios aos processos de formação veiculados nos ambientes virtuais de aprendizagem. In: MORAES, Maria Cândida; PESCE, Lucila; BRUNO, Adriana Rocha (Org.). Pesquisando fundamentos para novas práticas na educação online. São Paulo: RG, 2008. p. 55-74.

PESCE, L.; BRAKLING, K. Avaliação do aprendizado em ambientes digitais de formação de educadores. In: SILVA, M.; SANTOS, E. (Org.). Avaliação da aprendizagem em educação on-line. São Paulo: Loyola, 2006. p. 91-108.

POLÍTICAS públicas para a educação: olhares diversos sobre o período de 1995 a 2002. Educação \& Sociedade, Campinas, v. 23, n. 80, set. 2002. Número especial.

RONCA, Paulo A. C.; TERZI, Cleide. A Prova operatória. 17. ed. São Paulo: Edesplan, 1991.

SANTOS, Neide. Desafios da web: como avaliar alunos online. In: SILVA, Marco; SANTOS, Edmea (Org.). Avaliação da aprendizagem em educação on-line. São Paulo: Loyola, 2006. p. 245-265.

SILVA, Marco. O Fundamento comunicacional da avaliação da aprendizagem na sala de aula online. In: SILVA, Marco; SANTOS, Edmea (Org.). Avaliação da aprendizagem em educação on-line. São Paulo: Loyola, 2006. p. 23-36.

SOUZA, M. L. J. A Leitura na escola. In: Questões de linguagem. São Paulo: Contexto, 1991.

VOLOCHINOV, V. N.; BAKHTIN, M. Palavra própria e palavra outra na sintaxe da enunciação. Tradução Allan Tadeu Pugliese et al. São Carlos: Pedro e João, 1929-2011.

ZUIN, A. A.; PESCE, L. Razão instrumental, emancipação e formação online de educadores. In: SILVA, M.; PESCE, L. M.; ZUIN, A. A. (Org.). Educação online: cenário, formação e questões didático-metodológicas. 1.ed. Rio de Janeiro: Wak, 2010. p. 109-135. 


\section{LUCILA PESCE}

Universidade Federal de São Paulo. Doutorado em Educação:

Currículo, PUC/SP, Pós-doutorado em Filosofia e História da Educação, UNICAMP

lucilapesce@gmail.com; lucila.pesce@unifesp.br 